\title{
The Design of Central Heating System Based on A New Kind of Heat Exchanger and The Study of Its Control Strategy
}

\author{
Ning Yuan ${ }^{1, a}$, Jianhua Yang ${ }^{2, b}$ and Wei Lu ${ }^{3, c}$ \\ ${ }^{1}$ School of Electronic and Information Engineering,Dalian University of Technology,Dalian,China. \\ ${ }^{2}$ School of Electronic and Information Engineering,Dalian University of Technology,Dalian,China \\ ${ }^{3}$ School of Electronic and Information Engineering,Dalian University of Technology,Dalian,China \\ ayuanning@mail.dlut.edu.cn, bjianhuay@dlut.edu.cn, 'luwei@dlut.edu.cn
}

Keywords: Heat ex-changer, Central heating, Feed-forward control, Control Strategy.

\begin{abstract}
In order to solve the problem of central heating energy wasting and uneven heating,this paper presents a novel heat ex-changer(jet heat ex-changer) and designs a new central heating system compared with the traditional central heating system based on this new kind of heat ex-changer.This new central heating system can rapidly detect and regulate heat transfer station by using GPRS technology . So that the entire heating network can achieve better operational status and heating quality at the premise of high efficiency and low cost. Finally, the feed-forward control strategy is applied to this new central heating system and achieve better result compared with the traditional PID control strategy.
\end{abstract}

\section{Introduction}

Currently, the urban district heating in the winter in the north of China has become a major heating mode. By using the modern technology, we have researched and developed a new district heating system that has replaced the traditional distributed control system .The new district heating system not only saves resources, improves economic efficiency, reduces environmental pollution, but it also can enable the users to get a reasonable thermal heat distribution in the winter .So it can achieve the purposes of on-demand heating and uniform heating[1] .Central heating system is relatively dispersed in the geographical and it has dozens of heat transfer stations as many as hundreds of heat transfer stations. So how to detect the various conditions of heat transfer station and regulate the heating system timely and effectively to ensure heating requirements have become a very significant research topic. A company in Dalian has developed a new type of heat ex-changer and the new central heating system is designed based on this new type of heat ex-changer. We discussed the structure of this new heating system and the internal control strategy of the heat transfer station.

\section{Architecture of The New Central Heating System}

\section{Architecture of The Traditional Central Heating System}

The traditional centralized heating network system has to go through the heat exchange twice, including the heat exchange of first station and the heat exchange of second stations .The structure of traditional centralized heating network is shown in Fig 1. The more the times of heat exchange, the lower the utilization of resources and the more complex control strategies of the distributed measurement and control systems[2]. Thus, reducing the number of heat ex-changers is important to improve resource utilization.

\section{The Jet Heat Ex-changer}

A company in Dalian has developed an energy-saving and high-efficiency jet heat ex-changer. The Jet heat ex-changer broke the foreign technical barriers and widely used in our country's heating system. Compared with the conventional heat ex-changer, the new heat exchange canceled the pump sand rotating part and its thermal efficiency is close to $100 \%$. This will not only improve the utilization of hot steam, and also can save energy and reduce costs. 


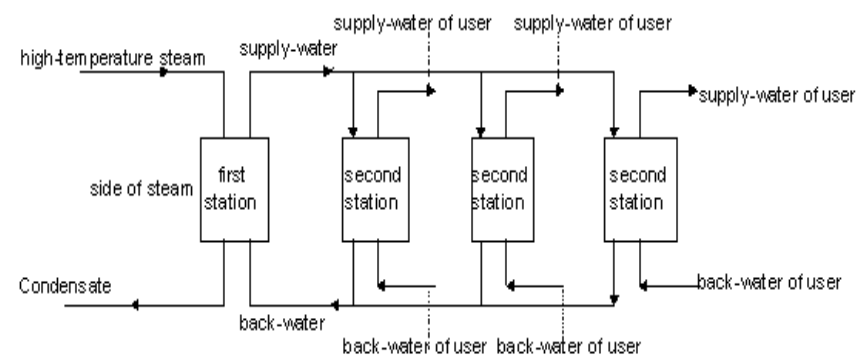

Fig. 1 The structure of traditional central heating system

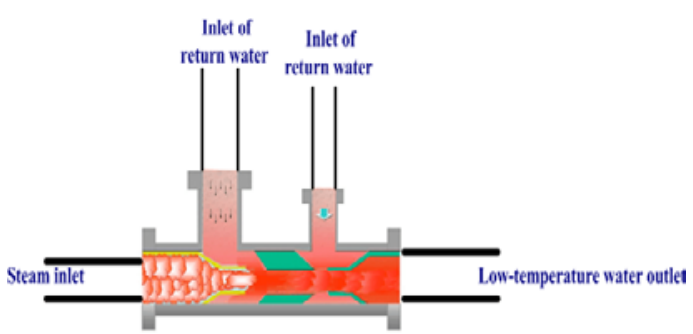

Fig. 2 The schematic of jet heat ex-changer

The jet heat ex-changer uses the steam as the heat resource and act through the process of injection, contraction and proliferation based on the Rafael principle. The heat ex-changer mingles a certain volume ratio of steam with back-water and forms a single-phase water[3]. Then the hot water that has been pressurized and heated can be transferred to the user's water supply piping system.

\section{Architecture of The New Distributed Control System}

The steam of thermal power plants and the backwater of heat users are mixed directly in the heat ex-changer, the heat ex-changer output directly the low-temperature water that can be supplied to the heat user and it can greatly improve the utilization of energy. The central heating system diagram based on the new heat ex-changer can be designed as the following structure in Fig 3.

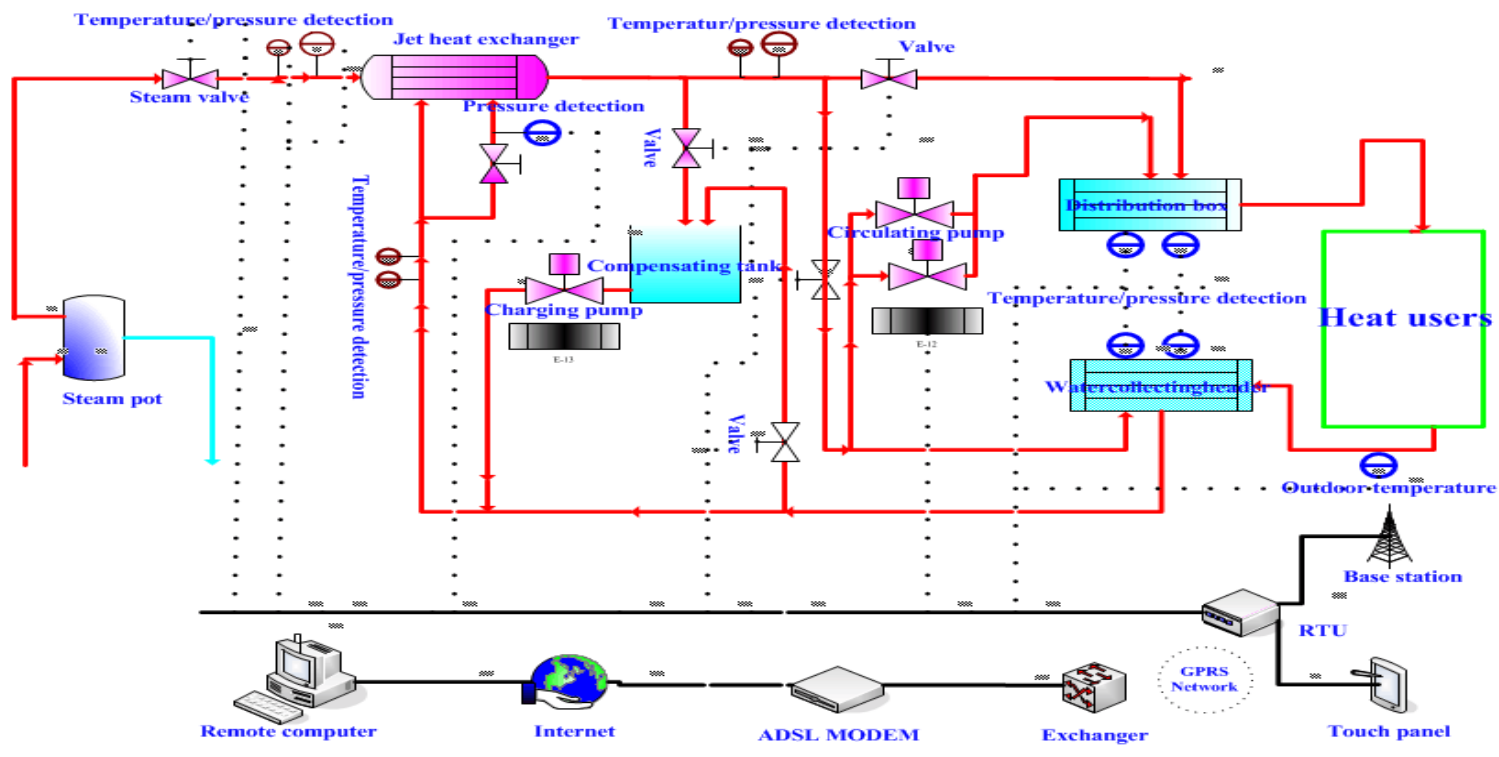

Fig. 3 The topology of new central heating system

The new central heating system based on heat ex-changer utilized the new jet heat and reduced the number of heat ex-change. It can not only make the control strategy more simple but also can improve resource utilization and saves resources. The high temperature steam of thermal power plant connects directly with the jet heat ex-changers through pipeline and the heat ex-changer output directly the low-temperature water $\left(70-80{ }^{\circ} \mathrm{C}\right)$ and supply the low-temperature water to the heat user. According to the characteristics of heating network, distributed central heating system can be managed and controlled by using a two-stage distributed measurement and control system, the structure can be shown in Fig 4. 


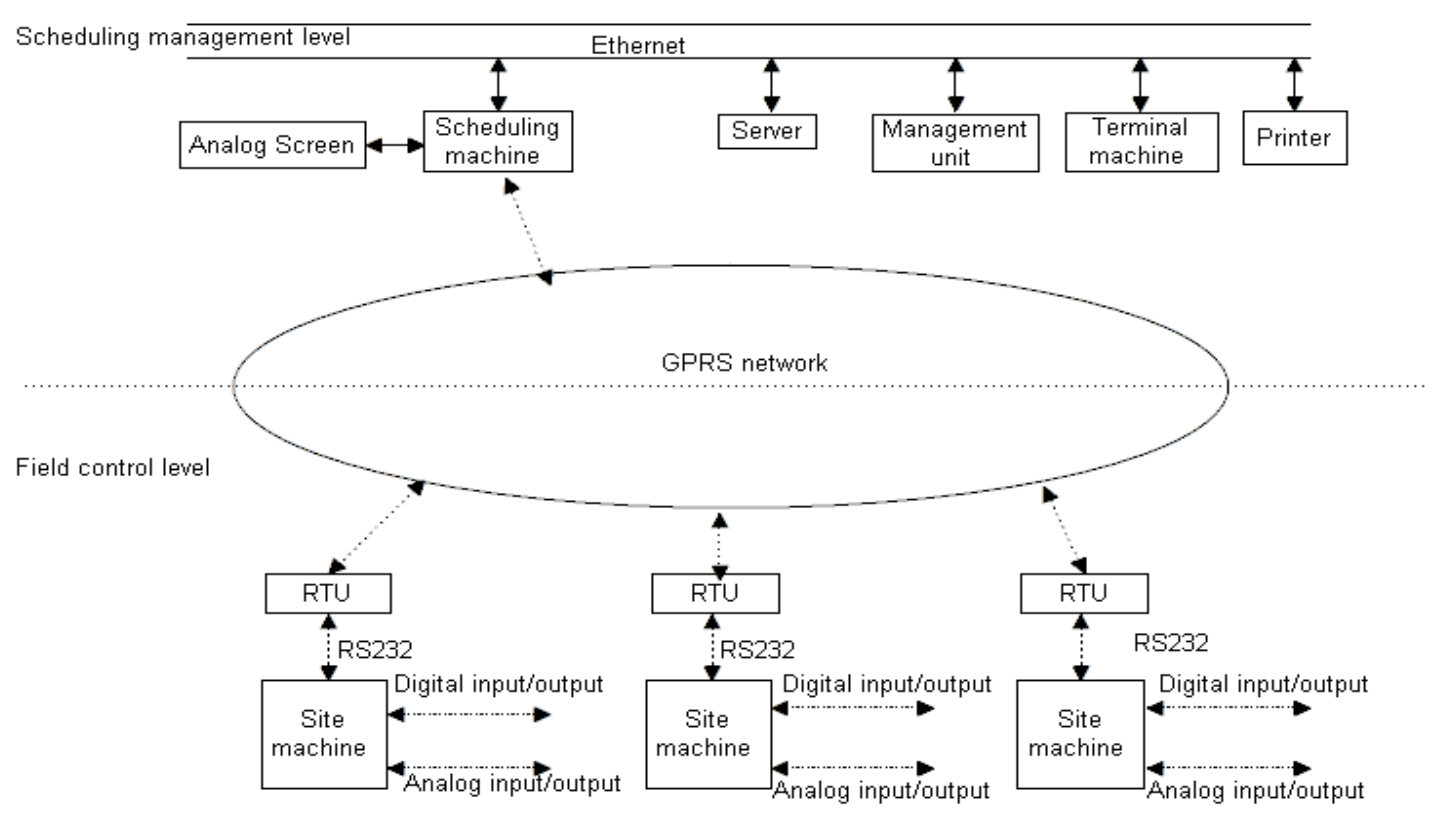

Fig. 4 Structure of the central heating network distributed control system

\section{Central Management Scheduling Level (CMSL)}

Central Management Scheduling Level is the PC platform software for the entire system, which is responsible for the management scheduling and the controlling task of the centralized heating network and the substation parameters' display. Central Management Scheduling Level which is named the central controlling room helps us realize the bidirectional communication with the Field Control Level[4]. By mastering the entire network operation parameters, we can analyze the degree of thermodynamic equilibrium of each substation and the most negative point used to predict and regulate the balance of the heat source and the heat load.

In the end, through sending instructions to the heat transfer station or the heat source based on the problem in the existing heat network to achieve the dynamic optimization of the heat network. Above that, the CMSL also have the ability to manage log and report forms, curves and the print. The automatic control heat ex-changer station plays a connecting link role, which can not only reflect operating conditions and equipment operation of the heat transfer station, but can also execute the commands accepted from the host computer automatically[5]. With the help of the CMSL, the Dispatchers can guarantee the operation of the heat network system with safety and low-cost. In order to realize these functions, the PC platform software should module as shown below:

(1)The monitoring module: regularly inspect working parameters of each heat transfer station via GPRS network.

(2)Operating management module: analyze the working state and make an real-time alarm.

(3)Control module: send instructions to the field equipment based on the parameters data delivered from the field to regulate the working state of field equipment and ensure the steady operation to realize the unattended operation.

(4)The guidance module: based on the reality of the field such as the weather condition and the heated squares to realize the heat load prediction, analyze and compare the real heated load with the predicted heat load.

\section{The Field Control Level (FCL)}

The Field Control Class that consists of the controller, touchscreen, RTU, handled panel and other equipment, is responsible for monitoring the heat substation which makes up of the heat ex-changer and water equipment.The field control module consists of a series of PLC which is responsible for the acquisition of parameters such as the water temperature, water pressure, the water level, the open degree and the pump switch status, etc and transmit these data to the host computer using the RTU(Remote Terminal Unit) via the GPRS network. The main functions of the FSL is described as below: 
(1) The field machine needs to collect the field parameters with fixed time and transmit the data to the host computer. The field controller sends the data that are stored, displayed and analyzed to the host computer every five minutes.

(2) Accept the instructions from the host computer and translate the instructions by the PLC into electrical current signal ranging between 4 to 20 to be acted on the executor to regulate the open degree of the valve. The water pump switch status is adjusted based on the switch signal.

(3) Intelligent converter helps finish the automatic control or hand control function to achieve the goal of removal of fault, and ensure the safe operation.

\section{The Control Strategy Study of Internal Heat Transfer Station}

\section{The Obtaining of Supply and Return Water Temperature}

The central heating network is a typical large inertia, strong coupling, large delay, nonlinear network and it is not easy to establish the mathematical model.The conventional PID control can not meet the control requirements of the network .In order to achieve the purpose of uniform heating and demand heating, it require a reasonable supply of the hot steam flow. So the controlled parameters are the user's hot water temperature $t_{g}$ and the adjusted parameters are the inlet valve of each jet steam heat ex-changer.According to the steady state conditions,the system of radiator's heat dissipation is equal to the heat supply of system and equal to the user's heating consumption. So we can obtain the supply and return water temperature with the indoor and outdoor temperature changing in this steady state conditions[6].

$$
\begin{aligned}
& t_{g}=t_{n}+\frac{1}{2}\left(t_{g}^{\prime}+t^{\prime}{ }_{h}-2 t_{n}\right)\left(\frac{t_{n}-t_{w}}{t_{n}^{\prime}-t_{w}^{\prime}}\right)^{1 /(1+B)}+2 \frac{1}{\bar{G}}\left(t_{g}^{\prime}-t^{\prime}{ }_{h}\right)\left(\frac{t_{n}-t_{w}}{t_{n}^{\prime}-t_{w}^{\prime}}\right) \\
& t_{h}=t_{n}+\frac{1}{2}\left(t_{g}^{\prime}+t^{\prime}{ }_{h}-2 t_{n}\right)\left(\frac{t_{n}-t_{w}}{t_{n}{ }_{n}-t_{w}^{\prime}}\right)^{1 /(1+B)}-2 \frac{1}{\bar{G}}\left(t_{g}^{\prime}-t^{\prime}{ }_{h}\right)\left(\frac{t_{n}-t_{w}}{t_{n}^{\prime}-t_{w}^{\prime}}\right)
\end{aligned}
$$

$t_{g}$ is the supply water temperature of heat user's, $t_{h}$ is return water temperature of the user's $. t_{n}, t_{w}$ is stand for indoor and outdoor temperatures, $t_{g}^{\prime}, t_{h}^{\prime}$ are the parameters for the design conditions, B is the radiator coefficient usually selected between 0.28 to $03, \bar{G}$ is the relative flow ratio of operating condition to the design condition. Therefore, the above design parameters are certain under a certain conditions of the outdoor temperature and we can calculated the supply water temperature and the return water temperature of heat user's.

\section{The Research Based on The Feed-forward Control Strategy}

In the central heating system, meeting the certain water pressure is the basic to achieve uniform heating and demanding. From the diagram of the Distributed Control System we can see that when the water pressure is insufficient the circulation pump's role is to extract some of the return water system to the water supply system, so that the water pressure can meet the requirements. Because of the return water temperature is lower than the supply water temperature, it is bound to cause the supply water temperature drops[7]. In order to make the return water temperature meet the heating requirements, the steam valve opening degree must be opened bigger to raise the water temperature of the outlet. The adjustment mode of general feedback control is shown in Fig 5. Due to the large hysteresis character of centralized heating system, if we still use the feedback control strategy to adjust the water temperature, the water temperature will not satisfy the heating needs within a relatively long period of time. Therefore, we should adjust the supply water temperature when the detected water pressure is insufficient, so that it will not cause heat shortage. The following we will introduce the feed-forward control with the development modern detection technology and computer control technology, the applications of feed-forward control are increasingly widespread. In the feedback system, the measurement is the controlled variable and compare it with a given value. While in the feed-forward system, the measurement is the amount of interference. In the temperature feedback system, the water temperature is controlled amount while the water pressure is the amount of interference[8]. When the pressure becomes lower, the frequency pump will open larger and it will 
definitely cause the water temperature drop. At this time we need to adjust the steam valve. The supply-water temperature feed-forward control chart can be shown in Figure 6.

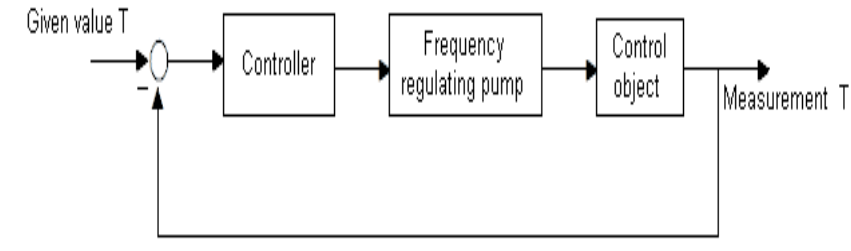

Fig.5 Temperature feedback control chart

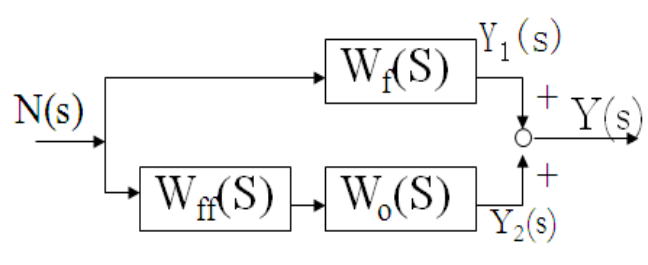

Fig.6 The block diagram of feed-forward control

\section{The Design of Dynamic Feed-Forward Controller}

The block diagram of feed-forward control can be show in Fig 6.

Which, $W_{f}(S)$-Disturbance channel transfer function

$W_{f f}(S)$-Feed-forward controller transfer function

$W_{O}(S)$ - Control channel transfer function which

Usually the characteristics of disturbance and control channel is a first order lag with pure inertia,

$$
\begin{aligned}
& W_{f}(S)=\frac{K_{f}}{1+T_{f} S} e^{-\tau_{f} S} \\
& W_{O}(S)=\frac{K_{O}}{1+T_{O} S} e^{-\tau_{O} S}
\end{aligned}
$$

Therefore, the transfer function is dynamic feed-forward controller is:

$W_{f f}(S)=-\frac{K_{f}}{K_{O}} \cdot \frac{1+T_{O} S}{1+T_{f} S} \cdot e^{-\left(\tau_{f}-\tau_{O}\right) S}=-K_{f f} \cdot \frac{1+T_{O} S}{1+T_{f} S} \cdot e^{-\left(\tau_{f}-\tau_{O}\right) S}$

Which , $K_{f f}$-gain of $W_{f f}(S)$

$$
K_{f} \text { - gain of } W_{f}(S)
$$

$K_{O}$ - gain of $W_{O}(S)$

Finally, we will discuss the controller transfer function parameters:

(1)When $T_{o}=T_{f}$, then $W_{f f}(S)=-\frac{K_{f}}{K_{O}} \cdot e^{-\left(\tau_{f}-\tau_{o}\right) s}$, the dynamic feed-forward controller is pure delay and it can be achieved. When $\tau_{f}<\tau_{o}$,dynamic feed-forward controller is pure advanced and it can not be achieved.

(2)When $\tau_{f}=\tau_{o}$, then $W_{f f}(S)=-\frac{K_{f}}{K_{o}} \cdot \frac{1+T_{O} S}{1+T_{f} S}$, while $T_{o}=T_{f}, W_{f f}(S)$ is proportional component. When $T_{o}>T_{f}, W_{f f}(S), W_{f f}(S)$ is advanced compensation characteristic. When $T_{o}<T_{f}, W_{f f}(S)$ is lag compensation characteristic[9].

\section{The Comparison of Feed-forward Control and PID Control}

Based on the previous discussion of the feed-forward controller parameters, we select $K_{f}=1, K_{O}$ $=10, T_{0}=10, T_{f}=20, \tau_{f}=15, \tau_{o}=12$ so the transfer function of the feed-forward controller is $W_{f f}(S)=-0.1 \times \frac{1+10 S}{1+20 S} \cdot e^{-3 S}$, the transfer function of the controlled object expression is $G(s)=\frac{8}{1+360 s} e^{-180 s}$, and the simulation results shown in Fi7 and Fig 8. 


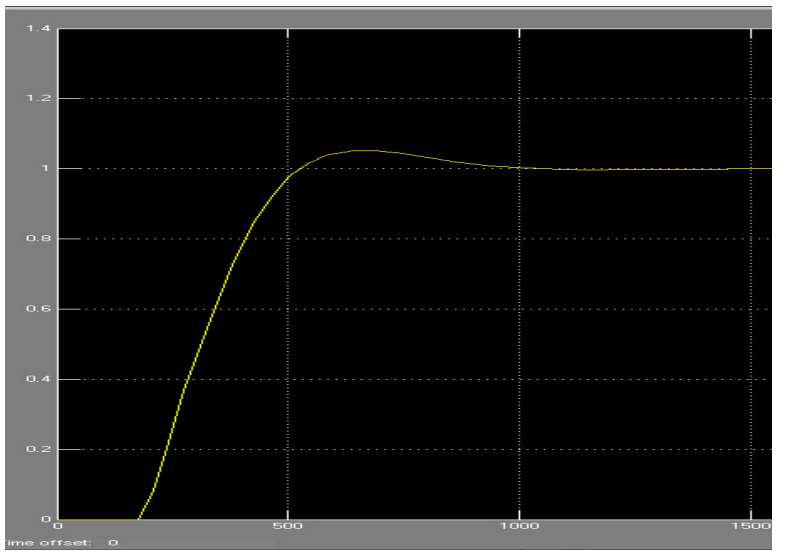

Fig.7 The simulation result of feed-forward control

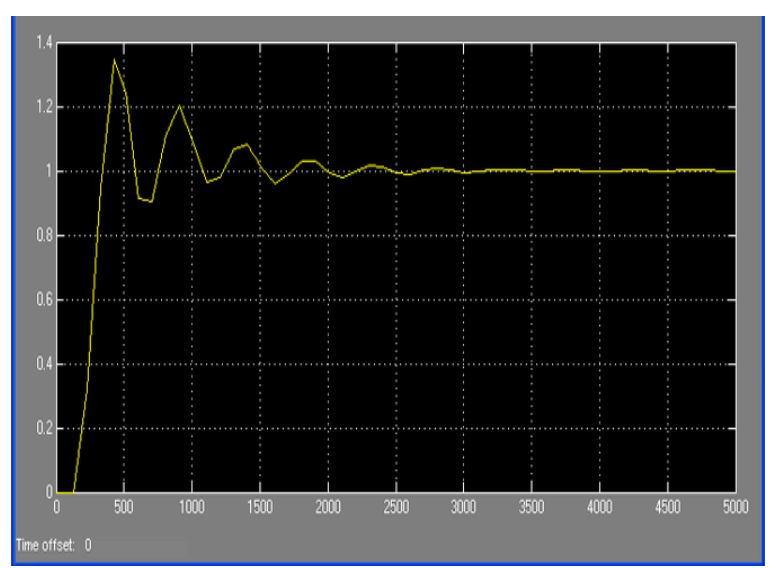

Fig.8 The simulation result of PID control

\section{Summary}

This paper proposes a new central heating system based on the new automatic heat ex-changer. It has realized the automatic control on the heat ex-changer station and let the field data transmit to the host computer by using GPRS technology[10]. Because of the bidirectional communication, we can also use the host computer to send instruction to the field equipment to control the open degree of the frequency conversion steam valve and finally achieve the automatic control. This paper also proposes the forward control strategy to overcome the delay of the original heating system. When the supply water pressure decreases, which will results the supply water temperature decreases, we use the pressure as the disturbance variable that can enable the forward controller to regulate the open degree of the steam valve to keep the supply water temperature ranges in the limited error. The forward feedback control strategy is proved to be more optimal than the PID control strategy in the experiment.

\section{Reference}

[1]Jiang X S, Jing Z X, Li Y Z, et al. Modelling and operation optimization of an integrated energy based direct district water-heating system[J]. Energy, 2014, 64: 375-388.

[2]Cui M H, Wang X, Liu J L. The Analysis of Plate Heat Ex-changer in Central Heating Regulation of Indirect Connection Hot Water Heating System[C]//Applied Mechanics and Materials. 2014, 584: 728-731.

[3]Zhang Jian, Dong-ling, Ma Ainong, Sun Hexu. GPRS based data acquisition system incentral heating[J]. Journal of LiaoNing Technical University. 2007.06: 885-888

[4] Liu Hongli,Li Qingming. Some Design Problems on Rebuild of District Heating Pipe Network. Shanxi Architecture.2006,32(2): 79-80

[5]Lou G H, Yin Y. Research and Realization of Remote Monitoring System for Central Heating [J]. Applied Mechanics and Materials, 2013, 427: 961-964.

[6]Zhang Yuwei,Lou Guohuan,Xiong Xisen.Research and Application of Heating Network Blanace in Central Heating Based on GSAA[J]. Procedia Engineering 23 (2011) 84 - 88

[7]Rijlaarsdam D, Nuij P, Schoukens J, et al. Frequency domain based nonlinear feed forward control design for friction compensation[J]. Mechanical Systems and Signal Processing, 2012: 551-562.

[8]Fan M M, Ma X C. Case Study about Overload Operation Regulation of Central Heating System [J]. Building Energy Efficiency, 2013, 4: 005.

[9]Lou G H, Yin Y. Research and Realization of Remote Monitoring System for Central Heating [J]. Applied Mechanics and Materials, 2013, 427: 961-964.

[10]Sun T Q, Nie Z H, Liu R. Study on Data Transmission System of Central Heating Based on 3G Wireless Network[J]. Applied Mechanics and Materials, 2011, 63: 333-336. 